\title{
Pertinence of reactive, active, and robust adaptation strategies in forest management under climate change
}

\author{
Rasoul Yousefpour $^{1}$ • Andrey L. D. Augustynczik ${ }^{1} \cdot$ Marc Hanewinkel $^{1}$
}

Received: 5 August 2016 / Accepted: 27 March 2017 / Published online: 4 May 2017

(C) INRA and Springer-Verlag France 2017

\begin{abstract}
- Key message Pertinence of alternative adaptation strategies to business as usual, namely reactive, active, and robust adaptation strategies, can be evaluated by incorporating the expected costs and benefits of adaptation, climate change uncertainty, and the risk attitudes of decision-makers.

- Context Forest management is used to coping with risky and uncertain projections and estimates. However, climate change adds a major challenge and necessitates adaptation in many ways.

- Aims This paper highlights the dependency of the decisions on adaptation strategies to four aspects of forest management: (i) the costs of mitigating undesirable climate change impacts on forests, (ii) the value of ecosystem goods and services to be sustained, (iii) uncertainties about future climate trajectories, and (iv) the attitude of decision-makers towards risk (risk aversion level).

- Methods We develop a framework to evaluate the pertinence of reactive, active, and robust adaptation strategies in forest management in response to climate change.
\end{abstract}

Handling Editor: Barry Alan Gardiner

Contribution of the co-authors

RY designed the research and wrote the draft. A.L.D.A. and MH both codeveloped the framework and wrote the paper.

Electronic supplementary material The online version of this article (doi:10.1007/s13595-017-0640-3) contains supplementary material, which is available to authorized users.

Rasoul Yousefpour

rasoul.yousefpour@ife.uni-freiburg.de

1 Chair of Forestry Economics and Forest Planning, University of Freiburg, Tennenbacher Str. 4, 79098 Freiburg, Germany
- Results Business as usual may still be retained if the value of the forest and cost of climate impacts are low. Otherwise, it is crucial to react and facilitate the resilience of affected forest resources or actively adapt in advance and improve forest resistance. Adaptation should be robust under any future climate conditions, if the value of the ecosystem, the impacts from climatic changes, and the uncertainty about climate scenarios are very high.

- Conclusion The decision framework for adaptation should take into account multiple aspects of forest management under climate change towards an active and robust strategy.

Keywords Adaptive management $\cdot$ Climate target $\cdot$ Forest growth $\cdot$ Climate risks $\cdot$ Forest economics

\section{Introduction}

Forest management is used to coping with risks and uncertainties inherent in forestry and future projections and estimates, e.g., storm damage, fluctuations in wood prices, and empirical projections about future stand volume and its increment. However, climate change adds a major source of risk and uncertainty to the previous challenges. Precise estimates of the timing and extent of climate change are still missing as well as comprehensive information regarding the vulnerabilities and adaptive capacity of forest ecosystems to these changing environmental conditions (IPCC 2014; Lindner et al. 2010; Bonan 2008). Climate affects forest growth and accordingly any change in climate may affect forest productivity. Moreover, climate change alters the frequency, scale, and intensity of disturbances (Allen et al. 2010; Landmann et al. 2015). The magnitude of damage from hazardous and climate-driven events to the forest and the direct climate-forest interaction affecting forest 
growth and productivity are both decisive parameters when defining the most suitable adaptation strategies.

Another added challenge related to climate change uncertainty, however, is the multiplicity of scenarios to project the climate development pathway in coming decades and the impossibility of assigning any probabilistic weight to these different climate trajectories. Dealing with this kind of deep uncertainty is one of the most crucial problems in developing appropriate adaptive strategies under climate change (Kwakkel et al. 2016). A set of plausible climate change scenarios is usually defined based on the assumptions about population growth, energy consumption, technological development, and land use changes in the twenty-first century. Scenarios may project a low, medium, or a large change in climate leading to $2-6{ }^{\circ} \mathrm{C}$ increase in average global surface temperature at the end of the century. Recent consensus on a climate target, e.g., Paris Agreement on a maximum $1.5-2{ }^{\circ} \mathrm{C}$ change in the global average surface temperature at the end of century, may reduce this deep uncertainty. However, actions to meet the climate target and their pathways as target-oriented scenarios will remain deeply uncertain.

Forests deliver a wide diversity of ecosystem goods and services. The more important the provisioning of these goods and services for the reliant community, the more crucial is it to sustain these ecosystems. Accordingly, it is highly recommendable to adapt the forests with a very high value to society in face of future environmental changes, i.e., maintaining forests essential for promoting the well-being of communities through the provisioning of goods and services. This might include both use and non-use values, such as timber production, carbon sequestration, biodiversity maintenance, and landscape beauty. Analyzing the costs of implementing essential adaptation strategies and added benefits from safeguarding resources and their services compared to a business as usual (BAU) management system may aid in deciding upon the most suitable adaptation strategy. Accordingly, a reactive adaptation strategy, an active adaptive strategy, or a robust adaptation strategy may be selected. We will outline these three adaptation strategies and their suitability depending on the value of ecosystem goods and services, costs of adaptation, and underlying risks and uncertainties related to climate change scenarios.

Moreover, we integrate the risk attitude of decision-makers in selecting these adaptation strategies. Risk-seeking decisionmakers may stick to the BAU strategy and avoid adaptation in the hope of either non-realization of climate change at all or a climate change realization with low impacts on their forests. However, forest decision-makers are mostly risk-averse (Sauter et al. 2016; Petucco et al. 2015) and would select an adaptation strategy. Selection of the most suitable adaptation strategy is dependent on the costs and benefits estimated from the implementation of adaptation. The more risk-averse the decision-makers are, the more robust the adaptation strategies should be, as they place more utility in obtaining benefits with high certainty, rather than risky investments that may yield higher benefits but with lower probability. In this sense, robust decision-making provides a framework to identify such options, with low sensitivity to uncertainty, trading optimality for robustness against outcome fluctuations (Lampert and Collins 2007).

In the following, we first outline the main aspects of climate change affecting forest growth and productivity and changes in the magnitude and frequency of forests disturbances. We clarify the nature of climate change and its uncertainty affecting decisions on adaptive strategies. We continue the paper with the proposal of guidelines for deciding on the selection of adaptation strategies regarding their potential outcomes (forest goods and services) and levels of safety for forest ecosystem sustainability. Subsequently, we analyze the dependency of decisions on adaptation strategies on the risk attitude (risk aversion degree) of decision-makers.

\section{Materials and methods}

We synthesize the impacts of climate change on forest resources especially in Europe based on the latest IPCC reports and studies investigating the impact of climate change on forest ecosystems. For this, we rely on the recent modeling results on the projection of future forest resource conditions and the scale of species distribution affected by climate change. We analyze the sensitivity of the modeling results to the employed climate change scenarios and highlight the implications of having no consensus about a single climate change scenario and the added complexity for decisionmakers to deal with the multi-scenario, i.e., deep uncertainty, situation. We review the current strategies to deal with risks and uncertainties associated with climate change considering management recommendations provided by studies investigating forest adaptive management options to climate change between 2000 and 2016 (see the list of literature consulted in Supplementary 1). We compare the advantages and shortcomings of these alternative strategies to BAU strategies.

Finally, we develop a framework based on Lawler (2009), adopting an economics-oriented analysis considering costs and benefits of adaptation measures, and including additional factors, namely the attitude towards risk and the uncertainty related to climate change. Moreover, we outline the dependency of decisions on adaptation strategies on the aspects involved in the process of adaptive decision-making under climate change. These aspects are as follows:

- The impacts of climate change on forest resources and the costs associated with the adaptive strategies to deal with these impacts 
- The value of forest resources and the benefits from applying any adaptive strategy to safeguard provisioning of ecosystem goods and services

- The uncertainty inherent in climate change defined as deep uncertainty about the probability of realizing each climate change scenario in the future

- Risk attitude (aversion degree) of decision-makers to risk or not adapting to climate change versus BAU

Depending on these four aspects, we allocate four different climate management strategies including BAU and three adaptation strategies namely reactive, active, and robust to climate change. Moreover, undertaking no active management at all may be considered as another adaptation strategy.

\section{Results}

\subsection{Climate change impacts}

To provide a common base for climate impact assessment, IPCC (2014) reports a few major scenarios about the future climate development called Representative Concentration Pathways (RCPs). The main outcomes of RCPs are the trends in climate change and the final level of global warming at the end of twenty-first century (van Vuuren et al. 2011). RCPs provide a common source of forcing for earth system models (ESMs) to simulate climate trajectories. Figure 1 illustrates four main RCPs realized by different ESMs to predict anomalies in global surface temperature. RCP8.5 is an extreme noclimate-policy scenario and RCP2.6 represents a rigorous climate policy to allow for a low climate change impact. Between these two extreme scenarios, there are RCP4.5 and RCP6.0 with moderate greenhouse gas (GHG) emissions and following effects.

These different emission pathways and their respective climate forcing imply a variety of impacts on forest ecosystems at different temporal scales. Transient changes in temperature, precipitation regimes, and $\mathrm{CO}_{2}$ concentration may trigger processes related to changes in growth and productivity, increased mortality, and areal shifts in species composition (Svenning and Sendel 2013; Meehl et al. 2013; Allen et al. 2010). With expected alteration in the frequency of extreme climatic events, abrupt impacts on forest ecosystems are expected, namely the frequency of disturbance regimes, e.g., wind damage, wildfires, and pest outbreaks (Alley et al. 2003; Seidl et al. 2014). These aspects of climate change will require a variety of management actions in order to guarantee the provisioning of ecosystem goods and services. Transient changes can be largely tackled through management interventions, such as adjusting thinning intensity to cope with changes in growth and to reduce mortality and promoting site-

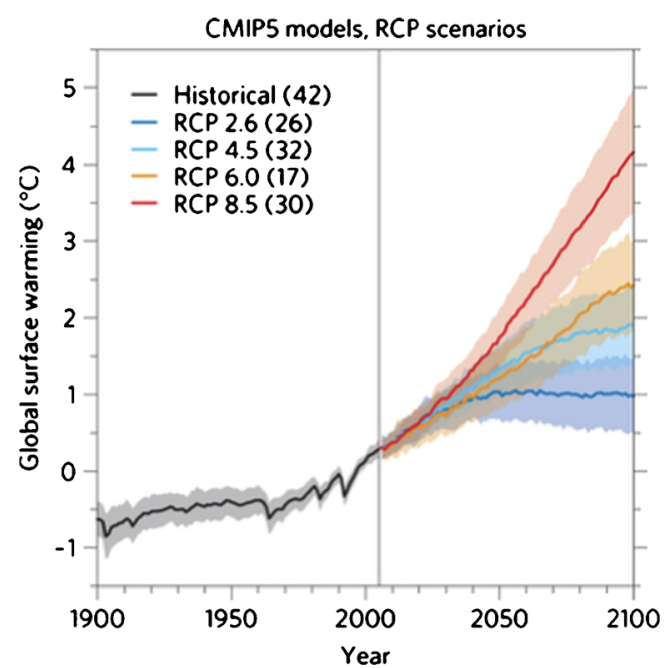

Fig. 1 Reported and projected changes in global surface temperature during 1900-2100 applying ESMs (the number in parenthesis is the number of participating models) in Coupled Model Intercomparison Project Phase 5 (CMIP5 Project)

Source: Knutti and Sedláček (2013)

adapted species in stand regeneration (Kellomäki et al. 2008; Spittlehouse and Stewart 2004; Innes et al. 2009). Abrupt changes are more complex and require adaptive management measures to promote diversity of stand structures and increase resilience but also the development of monitoring and contingency plans, taking into account new disturbances, not occurring under current conditions, may occur in the future (Janowiak 2014; Spittlehouse and Stewart 2004; Heller and Zavaleta 2009). Hereafter, we outline some of the most relevant impacts of climate change on forest ecosystems.

\subsubsection{Changes in growth and productivity}

Forest growth and productivity are directly affected by climate properties, e.g., increasing concentration of $\mathrm{CO}_{2}$ in the atmosphere, temperature, precipitation, and nitrogen deposition from the atmosphere. $\mathrm{CO}_{2}$ is a vital GHG in the photosynthesis process and its amplified availability may positively affect tree growth in forest sites with no nutrient limitation (Hickler et al. 2015). Changes in temperature and precipitation may prolong the growing season or suitability of new areas for the establishment of forest vegetation (Soja et al. 2007) or negatively effects forest growth by increasing mortality of trees (Battles et al. 2008) especially under heat or drought stress (Temperli et al. 2012). Based on a meta-analysis, as Schelhaas et al. (2015) showed, climate change leads to considerable changes in the growth and productivity of forests in Europe. The magnitude of changes differs not only for tree species but may also differ for the different regions in Europe, where they show different directions of the change. These impacts are directly related to a change of the suitability of the growing conditions of the main tree species and related 
biome shifts (see next section) and can be influenced by adaptive management strategies.

\subsubsection{Increased mortality}

Mortality caused by competition among tree species (e.g., stand density, species composition, regeneration establishment in mature closed stands) and hazards are processes affecting forest vegetation dynamics (Soja et al. 2007). One of the major impacts of climate change on forest ecosystems on a global scale is an increase in mortality. Allen et al. (2010) conclude that some of the world's forested ecosystems are already responding to climate change and raise concerns that forests may become increasingly vulnerable to higher background tree mortality rates and die-off in response to future warming and drought, even in environments that are not normally considered water-limited. Rigling et al. (2013) have shown that a change of the mortality pattern is the major driver of the vegetation shift from the originally drought adapted species Scots pine (Pinus sylvestris) to the subMediterranean species pubescent oak (Quercus pubescens Willd.) in Switzerland. A major scientific challenge is to detect the physiological mechanism behind mortality, either as hydraulic failure or carbon starvation (Sevanto et al. 2014). Adaptive management responses to influence mortality could consist of admixing tree species to pure stands of species more sensitive to changes in climatic conditions (Neuner et al. 2015) or to reduce the tree density to increase the water use efficiency of the remaining trees (Martın-Benito et al. 2010).

\subsubsection{Change of the disturbance regimes}

The frequency, intensity, and geographical distribution of disturbance agents have recently changed to a considerable extent, and this trend of increasing levels of disturbance is expected to continue in the future. Seidl et al. (2011) have shown that in recent decades, forest disturbance regimes have intensified markedly across Europe, resulting in a strong increase in damage from wind, bark beetles, and wildfires. Climate change was the main driver of the increase in area burnt, while changes in forest extent, structure, and composition particularly affected the change in wind and bark beetle damage. These increasing disturbances could strongly impact the forest carbon budget (Seidl et al. 2011) and may have contributed to the recently observed carbon sink saturation in Europe's forests (Nabuurs et al. 2013).

\subsubsection{Areal shifts of major tree species}

Climate change is a major driver of range shifts of many species, both plants and animals (Guisan and Zimmerman 2000). These species can either adapt to the new environmental conditions, migrate, or go extinct (Zimmermann et al. 2008). Trees, as long living organisms with limited abilities to migrate (Meier et al. 2012), are among the species most affected by this type of changes that will in the long run lead to considerable changes of the distribution of major tree species in many areas of Europe. Thus, a climate change induced shift of productive tree species may have severe economic consequences and lead to losses of the value of European forest land in the range of several hundred billions of Euros (Hanewinkel et al. 2013). One of the main challenges of forest management will therefore be to find alternatives to productive-mostly coniferous - tree species that are expected to disappear or move into areas with cooler and more moist climatic conditions (i.e., into northern latitudes or higher altitudes).

\subsection{Forest management strategies to deal with climate change}

To deal with climate impacts on forests, management strategies are proposed to adapt forests to forthcoming environmental changes and mitigate its negative effects (Yousefpour et al. 2012). Experiences with the outcomes of the recommended strategies and their effectiveness to improve resistance and resilience of forests under climate change are at an early stage and too early to be evaluated. An exception is BAU strategies, developed in the past to optimize the productivity of forest resources for wood utilization goals. However, these strategies are highly restricted to the stable climate of the past relying on climate-deterministic and empirical forest growth predictions, e.g., yield tables. Moreover, forest conservation, defined as no active management, may be classified as "passive adaptation," i.e., to account for natural adaptation potential of forest resources, e.g., genetic adaptation by abandoning forest areas (Bolte et al. 2009). In the context of climate change, this strategy may be a counterproductive, as valuable species from an ecological point of view may be lost without management support, due to changing environmental conditions. Therefore, ignoring climate change impacts using passive adaptation may result in forest resource degradation. Occasionally and if the adaptive capacity of a forest, e.g., genetic diversity and spontaneous adaptation, are so high that they become less vulnerable to climate change and impacts, conservation may be an adaptation alternative. However, this strategy may suffer from under-provisioning of forest goods and services directly used by surrounding communities, e.g., local timber industry (Petucco et al. 2015) as well as from increasing vulnerability of forests to disturbances, e.g., fire (San-Miguel-Ayanz et al. 2013). Therefore, in the following, we describe the potential expected outcomes of altering BAU to different alternative adaptation strategies, i.e., reactive, active, and robust adaptation. 


\subsubsection{Reactive adaptation}

Reactive adaptation recommends the postponing of actions on climate change and its impacts until the realization of negative effects. We recognize this strategy as "wait-and-see" approach in line with the decision-making method Real Options (Bowman and Moskowitz 2001) or Quasi Options (Brunette et al. 2014; Guest 2010). This adaptation strategy can be effective if the foreseen damages are not irreversible (Lempert and Collins 2007; Yousefpour et al. 2012). Moreover, waiting for the realization of climate change and impacts may improve the knowledge pool and consequently increase the efficiency of decisions on adaptation (Heal and Kriström 2002). This is very much appreciated if the decisions are irreversible or expensive. However, similarly to BAU strategies, it is very difficult to preemptively calculate the value of forthcoming information and prove the superiority of waiting and reacting over active adaptation.

\subsubsection{Active adaptation}

Active or pro-active adaptation is the most recommended and studied adaptation strategy in the literature (cf. Bolte et al. 2009). Recommendations in line with this strategy include a diversity of management actions, e.g., silvicultural interventions, changes in rotation age, target diameter for harvest, selection of tree species for regeneration, and establishment of novel and better-adapted provenances. Most of the recommendations, however, are conditional to a closed set of climate change and may not suffice if the magnitude of changes exceeds the considered level of climate change. This is a crucial aspect, as depending on the degree of changes in climate and its impacts and disturbance regimes, active adaptation strategy may lead eventually to fundamentally different recommendations. Active adaption could be developed for the "most-likely" climate change scenario. However, there is usually no consensus among scientists, decision-makers, and politics about any particular "most-likely" scenario. Instead, there are beliefs, being subjective judgments about the probability of realizing one or another scenario. Dealing with this level of deep uncertainty requires application of robust decisionmaking approaches.

\subsubsection{Robust strategy}

Making robust decisions under climate change may be an ultimate goal in forestry. A robust strategy would continuously perform satisfactorily under all climate change scenarios but not necessarily being optimal for each scenario. In this sense, there is a dilemma between the degree of robustness, reduction in uncertainty of climate change, and the costs of applying robust strategies. Robust decision-making refers traditionally to the decision-making process of finding suitable solutions under deep uncertainty that perform well over a wide range of plausible futures (Lempert et al. 2003). According to Hall et al. (2012), robust decision-making might involve a variety of approaches for assessing robustness of responses, including analytic, qualitative, and heuristic methods, e.g., robust optimization and qualitative scenario analysis. One way to find the robust decisions is to ask experts to judge the robustness of decision alternatives. Moreover, there is a set of stylized and quantitative robustness indicators applied in analytic methods to find a robust solution. Herman et al. (2015) identify two main classes of robust measures, namely regret and satisficing approaches. The former seeks for minimizing deviations compared to an ideal scenario (e.g., a management regime with best performance in case the most unfavorable climate change scenario becomes true) and the latter aims at maximizing the number of scenarios in which defined performance thresholds are met, e.g., maximizing the number of climate change scenarios in which the forest income level is above an established threshold (Hadka et al. 2015). Therefore, informing decision-makers about tradeoffs and robustness of different management alternatives, aiming for guaranteeing the achievement of a least expectation in any future condition, is the essence of robust decision-making approaches (Hall et al. 2012).

\subsection{A framework for the allocation of adaptation strategies}

We propose a framework for making decisions for any of the abovementioned adaptation strategies regarding four different aspects of forest management under climate change. A primary driving aspect is the effect of climate change on forest growth and the extent of negative impacts by changing disturbance regimes and the associated costs to mitigate undesirable outcomes. The lower the impacts, the more credible it is to just rely on the optimized BAU strategy and eventually react by a low-cost adaptation. For example, Bowman et al. (2013) indicate that climate change has a low likelihood of causing significant impacts on fire-resistant eucalypt forest types, and thus, alteration of BAU fire control practices may not be justified. Value of forest resources is the second aspect involved in deciding upon adaptation strategies. Therefore, a cost-benefit analysis of implementing adaptive management actions is warranted. Once the benefits for adapting overtake costs of not adapting, it is recommended to select an adaptive strategy. This rule applies throughout the set of adaptation strategies and differentiates them from BAU as illustrated in Fig. 2. Thus, the main axes (benefits of climate change adaptation and costs of climate change adaptation) of Fig. 2 act as a guide to decide whether or not to implement adaptive management actions, while the two supporting axes (climate change uncertainty and risk aversion) support the decision-making of which adaptive strategy to adopt. 


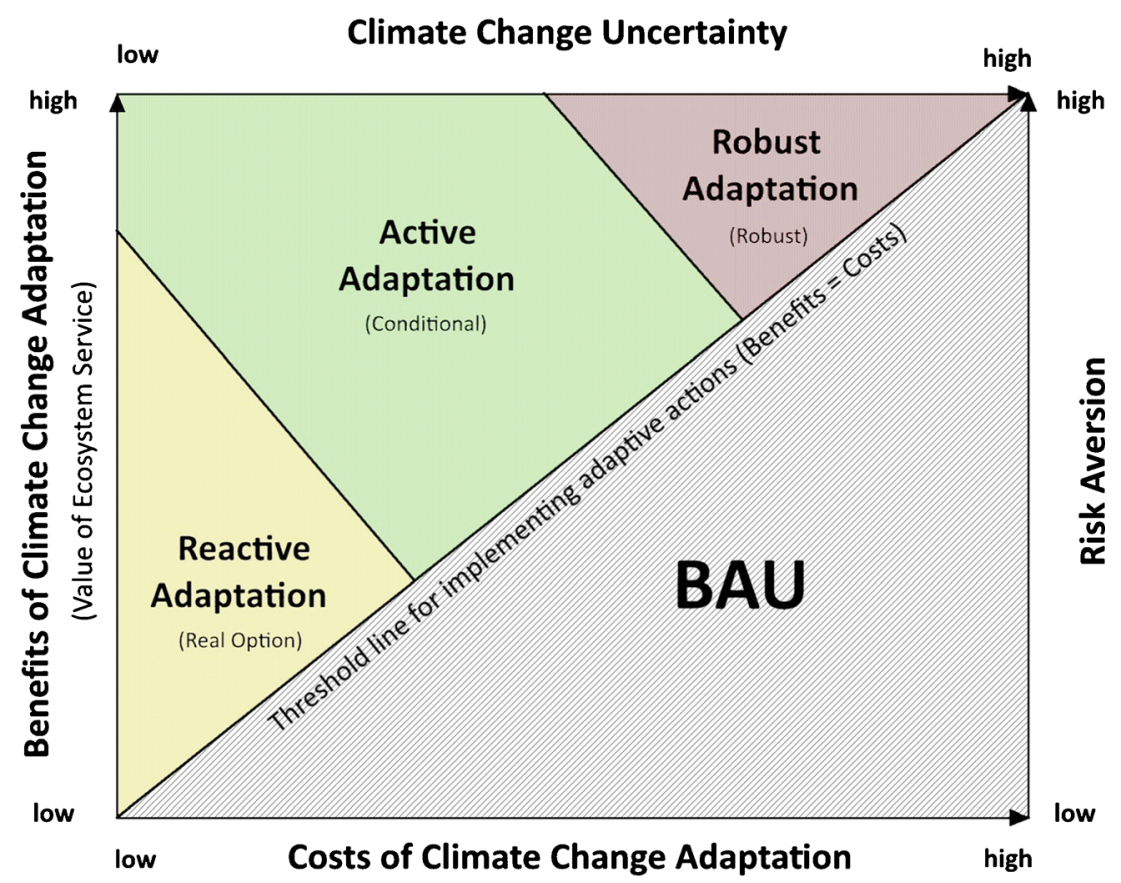

(Severity of Climate Change Impacts)

Fig. 2 Schematic allocation of four different adaptation strategies in relation to costs and benefits of adaptation to climate change, uncertainties associated with climate change and the role of decisionmakers' risk attitudes (risk aversion). BAU is implied only if the costs of adaptation exceed the benefits, and otherwise it is worth adapting. Reactive strategy is suitable for low-cost adaptation and if the foreseen climate change impacts and damages are not irreversible. Otherwise,

To select one of the three adaptation strategies, a third aspect is decisive. It is simultaneously the certainty that climate change will have impacts on the ecosystem and the uncertainty associated with the projection of these future climate conditions, as climate development may take a diversity of pathways, e.g., RCPs, without any knowledge of how to assign any probability to their realization and a very high variation in models outputs (IPCC 2014). Recognition of this deep uncertainty necessitates reactive, active, or robust adaptation for low, moderate, and high value forest resources, respectively. In this context, a reactive adaptation is selected if managers are confident that climate change impacts will not significantly affect the provisioning of goods and services, e.g., in areas where the temperature and precipitation regimes are predicted to stay relatively stable in the future and with less valuable forest resources. Thus, delaying the investment is intended to increase the knowledge regarding climate development and reduce uncertainty. Koning et al. (2014) conducted a survey on six European countries regarding forest conservation and management for Natura 2000 under climate change and recognized reactive adaptation as a preferred adaptation option for certain groups of forest managers. These managers believed climate change will not necessarily have negative impacts and were unwilling to make large investments for adaptation in the moment, i.e., they favored low-cost adaptation. active adaptation would be more suitable. Robust adaptation is the most costly strategy. However, it guarantees provisioning of forest ecosystem services under all climate change scenarios. The degree of risk aversion of decision-makers defines their attitude towards taking the risk of not adapting (low-risk aversion) or making sure of adapting to climate change (high-risk aversion)

On the other hand, an adaptive strategy is warranted with increasing uncertainty regarding climate development, expected negative impacts on forest ecosystems, and higher value of forest resources. For instance, Zubizarreta-Gerendiain (2015) propose a set of management actions, including modifying timing of thinning and final cut of boreal forests in central Finland, in order to maximize forest net present value (NPV), based on simulations considering the A1B emission scenario. Nevertheless, due to their conditional nature, adaptive actions may be risky if the considered climate change scenario does not occur. Not adapting, i.e., applying BAU, may be also risky and should be considered only if benefits of adaptation strategies are lower than the costs of adaptation. In this sense, the fourth aspect to be taken into account is a behavioral study of decision-makers attitude towards risk and their degree of risk averseness. The more risk-averse the decision-makers, the more likely they will be to adapt and the more they will favor robust strategies rather than adaptive and reactive strategies, thus guaranteeing a minimal level of provisioning of ecosystems goods and services, regardless of the future climate realization. We highlight that in the upper right corner of Fig. 2, the uncertainty is so high that risk-averse decision-makers are very unlikely to choose BAU over a robust strategy. Yousefpour and Hanewinkel (2016) propose an application of robust decision-making approaches for 
planning the species composition of valuable stands in central Europe under deep climate uncertainty. Their result recommends selecting Scots pine (P. sylvestris) because its average economic outcomes under three different climate change scenarios outperform beech (Fagus sylvatica) and Norway spruce (Picea abies) which are optimal under specific climate change scenarios.

\section{Discussion}

\subsection{Future research and adaptation strategies}

Application of BAU strategies for forest management is still predominant at the global level (Bernier and Schoene 2009). However, BAU strategies are commonly optimized for a single objective, e.g., timber production (Briceño-Elizondo et al. 2008), and are valid under stable climate conditions by using empirical yield tables (Lindner 2000). In this sense, even multi-purpose forest management, e.g., close-to-nature forestry largely applied in central Europe, is designed under stable climatic conditions and may show suboptimal in the future. Therefore, their optimality under changing environmental conditions is highly uncertain (Yousefpour et al. 2012). Reacting to climate change by applying ad hoc measures, different from BAU, to mitigate damages has been debated as a way of adaptation (Bolte et al. 2009). However, the base is BAU and may suffice if the degree of changes and their impacts are limited, e.g., removing damaged trees from snow breaks and fuel management for avoiding wildfires in susceptible areas (Amiro et al. 2001; van Gameren and Zaccai 2015).

Active adaptation occupies a large body of recent studies (e.g., Wagner et al. 2014; Temperli et al. 2012) by proposing a set of silvicultural and strategic actions to improve resistance and resilience of ecosystems facing climate change and its impacts. Safeguarding provisioning of multiple ecosystem services may be possible by these adaptation measures. However, the proposed measures are mostly conditional on certain climate outcomes (e.g., Temperli et al. 2012; GarciaGonzalo et al. 2007). Moreover, measures proposed for reducing forest vulnerability are based on the occurrence of recently occurring damage, e.g., bark beetle outbreaks, storm damage, and landslides (Seidl et al. 2009; Schlyter et al. 2006), and commonly disregard the possibility of occurrence of new catastrophic events such as forest fires due to drier climate conditions.

Considering the possibility of poor outcomes of adaptive actions due to its conditional nature, a novel adaptation strategy is emerging to make robust adaptive decisions for forest management (Pasalodos-Tato et al. 2013) borrowed from the engineering sector (Gabrel et al. 2014). Application of robust decision-making to forestry is very rare (e.g., Palma and Nelson 2009). However, there is a long existing strategy that may be regarded as robust adaptation, namely portfolio management (Dittrich et al. 2016). These diversification of management strategies may be recognized as a simple and effective strategy to cope with climate change and build upon a portfolio of adaptation measures (Dragicevic et al. 2016; Härtl et al. 2015). The downside of this strategy is, however, sacrificing optimality for less sensitivity to false assumptions and hoping for partial safeguarding of forest resources and services under any future conditions (Lempert and Collins 2007). Other approaches are recommended in the literature, e.g., an option-oriented (i.e., "flexibility") management (Wilson and Baker 2001), a "complex adaptive system" to improve resilience of forest resources (Puettmann et al. 2013), and analyzing trade-offs between service provisioning and adaptability applying deterministic decision-making (Wagner et al. 2014) containing implicitly some notions of robustness. We recommend making robust and active adaptation strategies and the development of related frameworks and modeling systems to guarantee sustainable provisioning of forest goods and services. Moreover, we identify that an overlap between the adaptation strategies may occur. Here, we refer to the dominating strategy concept and highlight that even though a robust strategy may be considered a subset of active options, its particularity of being less sensitive to future climate warrants a differentiation as there are clear situations in which this strategy is more suitable than the usual adaptive actions considering single management scenarios (e.g., under deep uncertainty). Likewise, reactive management includes BAU but its application is warranted under certain conditions, e.g., when a low-cost adaptation is required. In this sense, we aim at characterizing these situations rather than strictly categorizing the adaptation strategies.

Figure 3 illustrates the current quantity and complexity of discussed strategies in the literature and highlights our recommendations about the future direction of research and practice towards robust and active adaptation. Robust decisions may apply different metrics to evaluate the robustness of alternative strategies. In the class of regret approaches, a typical choice is guaranteeing performance in the worst case scenario, e.g., safety-first criterion maximizing the expected utility of decision-makers subject to a certain minimum level of achievement in the worst case. Satisficing approaches might include maximizing the value-at-risk given a certain risk level, e.g., guaranteeing that in $95 \%$ of the plausible futures a certain performance threshold (e.g., minimum NPV or IRR) will be met. Additionally, a typical option for satisficing approaches is the minimization of the probability of catastrophic events, known as Conditional-Value-at-Risk (CVaR). The former measures are commonly applied in robust optimization and portfolio optimization (Ben Tal et al. 2009). We outline that selecting the robustness criterion is dependent upon decisionmakers regarding their risk attitude and risk management strategy. 


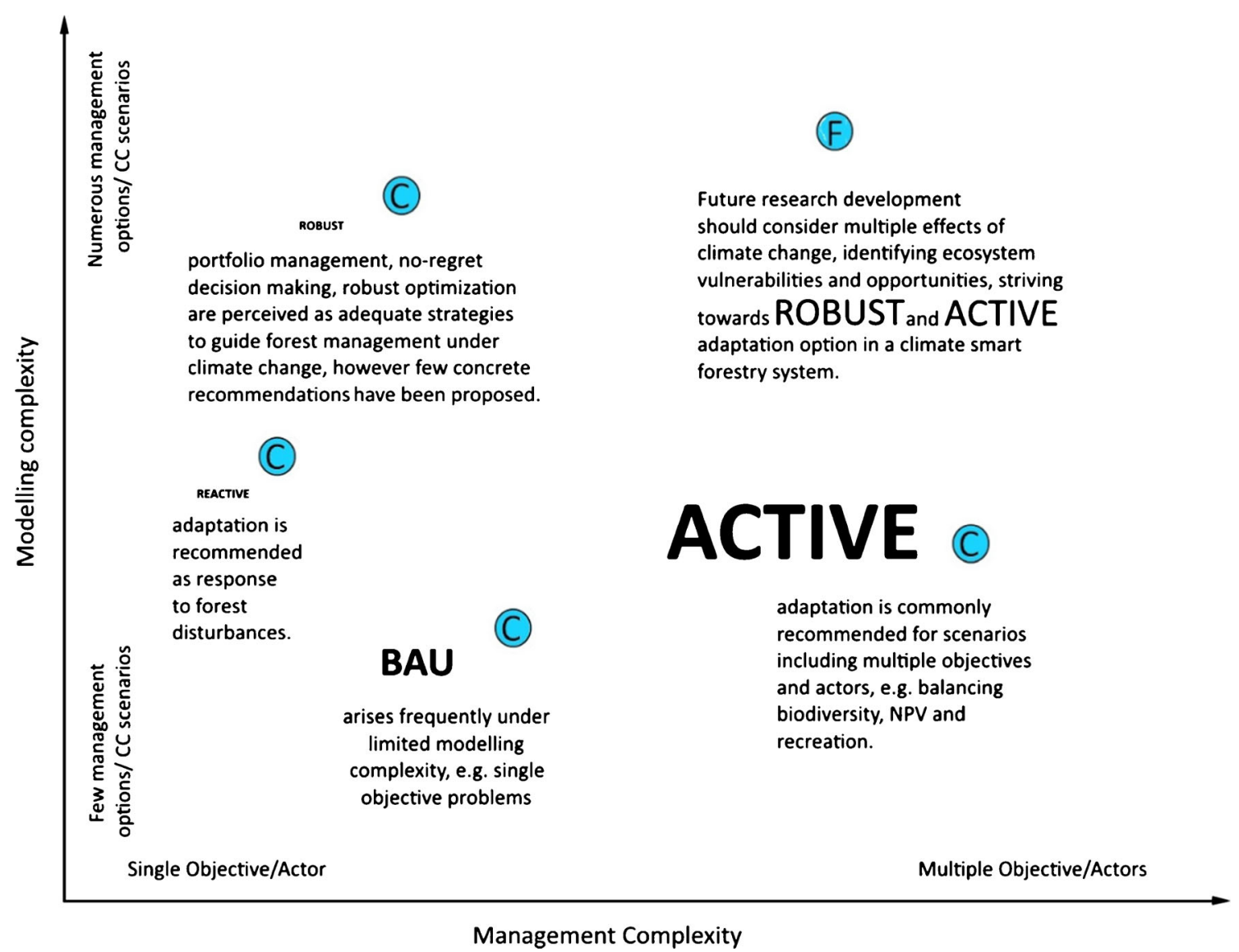

Fig. 3 Chart illustrating current $(C)$ and future $(F)$ states of research on the application of adaptation strategies under climate change. Font size shows the quantity of available literature $(\mathrm{BAU}=19$; active $=39$; reactive $=6$; robust $=6$ )

\subsection{Change in forest decision framework}

The facts about the deep uncertainty regarding the direction of climatic changes imply application of dynamic decisionmaking approaches, i.e., making use of novel information becoming available with time (Yousefpour et al., 2012). New decisions should revisit the former decisions and account for novel information from established monitoring systems and regard any changes in the decision framework, e.g., commitments about climate protection in the forest sector. International agreements on the climate target (e.g., Paris Agreement (UNFCCC 2015)) should reduce the deep uncertainty about the degree of climate change at the end of twenty-first century (Yousefpour and Hanewinkel 2016). Thereafter, decisions would move towards the most costeffective strategies for adaptation to the pathway leading to the agreed target climate.

Besides the environmental aspects that drive the choice of adaptive management actions, environmental governance also plays an important role. Creating an environment that facilitates managers to adapt is crucial. In this sense, the paradigms of environmental governance have been shifting recently towards an adaptive governance, aiming to increase the flexibility of social ecological systems and providing the opportunity to better cope with environmental changes and uncertainty (Chaffin and Gunderson 2016). Concurrently, environmental policy focus is moving towards learning and collaboration processes rather than top-down decision-making (e.g., Armitage et al. 2009). In addition, these novel approaches require that management objectives include the preferences of multiple actors, thus calling for multi-objective forest planning and balancing conflicting objectives (e.g., Diaz-Balteiro et al. 2009).

\section{Conclusion}

Adaptive forest management has been recently a major area of research in Europe and elsewhere (Keenan 2015). We categorize the adaptation strategies into four main approaches: BAU, reactive, active, and robust. We highlight that BAU and reactive measures after realizing any disturbance from climate change may apply in cases of low climate effects, low forest goods and service values, or a high cost of adaptation. Active adaptation occupies the major part of already developed studies. However, they are mainly concentrated on interventions 
being optimal for a specific climate outcome in the future and accordingly they may put at risk the provisioning of highly valuable forest goods and services. We recommend and borrow a newly emerging field of decision science for developing robust strategies to ensure future provisioning of services. Furthermore, we are experiencing a novel political consensus about a climate target at the end of twenty-first century (e.g., max. $2{ }^{\circ} \mathrm{C}$ increase in global surface temperature). Action pathways, i.e., scenarios, to meet the climate target would be a different source of deep uncertainty in relation to climate change pertaining to robust decision-making approaches. As robust adaptation is a missing approach in forestry literature (except for portfolio management which is a type of robust decision-making approach), future studies should focus on providing good examples of robust adaptation in forestry (see e.g., Yousefpour and Hanewinkel 2016).

Acknowledgements We are grateful for the constructive comments made by associate editor Dr. Barry Gardiner and three anonymous reviewers and improved the manuscript. Moreover, we acknowledge that this study benefited from participation of authors in SuFuRun project (http://suforun.ctfc.cat/) funded by European commission with grant agreement Number 691149

\section{References}

Allen CD, Macalady AK, Chenchouni H, Bachelet D, McDowell N, Vennetier M, Kizberger T, Rigling A, Breshears DD, Hogg EH, Gonzalez P, Fensham R, Zhang Z, Castro J, Demidova N, Lim JH, Allard G, Running SW, Semerci A, Cobb N (2010) A global overview of drought and heat-induced tree mortality reveals emerging climate change risks for forests. For Ecol Manag 259:660-684

Alley RB, Marotzke J, Nordhaus WD, Overpeck JT, Peteet DM, Pielke RA, Pierrehumbert RT, Rhines PB, Stocker TF, Talley LD, Wallace JM (2003) Abrupt climate change. Science 299:2005-2010

Amiro BD, Stocks BJ, Alexander ME, Flannigan MD, Wotton BM (2001) Fire, climate change, carbon and fuel management in the Canadian boreal forest. Int J Wildland Fire 10:405-413

Armitage DR, Plummer R, Berkes F, Arthur RI, Charles AT, Davidson-Hunt IJ, Diduck AP, Doubleday NC, Johnson DS, Marschke M, McConney P, Pinkerton EW, McConney P (2009) Adaptive co-management for social-ecological complexity. Front Ecol Environ 7:95-102

Battles JJ, Robards T, Das A, Waring K, Gilless K, Biging K, Schurr F (2008) Climate change impacts on forest growth and tree mortality: a data-driven modeling study in the mixed conifer forest of the Sierra Nevada, California. Clim Chang 87:193-213

Bernier P, Schoene D (2009) Adapting forests and their management to climate change: an overview. Unasylva 60:5-11

Bolte A, Ammer C, Loef M, Madsen P, Nabuurs G, Schal P, Spathelf P, Rock J (2009) Adaptive forest management in central Europe: climate change impacts, strategies and integrative concept. Scand J For Res 24:473-482

Bonan GB (2008) Forests and climate change: forcings, feedbacks, and the climate benefits of forests. Science 320:1444-1449

Bowman DM, Murphy BP, Boer MM, Bradstock RA, Cary GJ, Cochrane MA, Fensham R, Krawchuk MA, Price OF, Williams RJ (2013) Forest fire management, climate change, and the risk of catastrophic carbon losses. Front Ecol Environ 11:66-68
Bowman EH, Moskowitz GT (2001) Real options analysis and strategic decision making. Organ Sci 12:772-777

Briceño-Elizondo E, Jäger D, Lexer MJ, Garcia-Gonzalo J, Peltola H, Kellomäki S (2008) Multi-criteria evaluation of multi-purpose stand treatment programmes for Finnish boreal forests under changing climate. Ecol Indic 8:26-45

Brunette M, Costa S, Lecocq F (2014) Economics of species change subject to risk of climate change and increasing information: a (quasi-) option value analysis. Ann For Sci 71:279-290

Chaffin BC, Gunderson LH (2016) Emergence, institutionalization and renewal: rhythms of adaptive governance in complex socialecological systems. J Environ Manag 165:81-87

Diaz-Balteiro L, Gonzalez-Pachon J, Romero C (2009) Forest management with multiple criteria and multiple stakeholders: an application to two public forests in Spain. Scand J For Res 24:87-93

Dittrich R, Wreford A, Moran D (2016) A survey of decision-making approaches for climate change adaptation: are robust methods the way forward? Ecol Econ 122:79-89

Dragicevic A, Lobianco A, Leblois A (2016) Forest planning and productivity-risk trade-off through the Markowitz mean-variance model. Forest Policy Econ 64:25-34

Gabrel V, Murat C, Thiele A (2014) Recent advances in robust optimization: an overview. Eur J Oper Res 235:471-483

Garcia-Gonzalo J, Peltola H, Briceño-Elizondo E, Kellomäki S (2007) Effects of climate change and management on timber yield in boreal forests, with economic implications: a case study. Ecol Model 209: 220-234

Guest R (2010) The economics of sustainability in the context of climate change: an overview. J World Bus 45:326-335

Hall JW, Lempert RJ, Keller K, Hackbarth A, Mijere C, McInerney DJ (2012) Robust climate policies under uncertainty: a comparison of robust decision making and info-gap methods. Risk Anal 32:1657-1672

Hanewinkel M, Cullmann D, Schelhaas MJ, Nabuurs GJ, Zimmermann NE (2013) Climate change may cause severe loss in economic value of European forestland. Nat Clim Chang 3:204-207

Härtl FH, Barka I, Hahn WA, Hlásny T, Irauschek F, Knoke T, Lexer MJ, Griess VC (2015) Multifunctionality in European mountain forests - an optimization under changing climatic conditions. Can J For Res 46:163-171

Heal G, Kriström B (2002) Uncertainty and climate change. Environ Resour Econ 22:3-39

Heller NE, Zavaleta ES (2009) Biodiversity management in the face of climate change: a review of 22 years of recommendations. Biol Conserv 142:14-32

Herman JD, Reed PM, Zeff HB, Characklis GW (2015) How should robustness be defined for water systems planning under change? J Water Resour Plan Manag 141. doi:10.1061/(ASCE)WR.19435452.0000509

Hickler T, Rammig A, Werner C (2015) Modelling CO2 impacts on forest productivity. Current Forestry Reports 1:69-80

Innes J, Joyce LA, Kellomaki S, Louman B, Ogden A, Parrotta J, Thompson I, Ayres M, Ong C, Santoso H, Sohngen B, Wreford A (2009) Management for adaptation. In: Adaptation of forests and people to climate change. IUFRO World Series Volume 22, Helsinki, pp 135-185.

IPCC. Impacts, adaptation, and vulnerability (2014) part a: global and sectoral aspects. In: Field, CB et al., eds, Climate change 2014: contribution of working group II (WG2) to 5th assessment report (AR5), Cambridge University Press, Cambridge, pp 1-32.

Janowiak MK, Swanston CW, Nagel LM, Brand LA, Butler PR, Handler SD, Shannon DP, Iverson LR, Matthews SN, Prasad A, Peters MP (2014) A practical approach for translating climate change adaptation principles into forest management actions. J For 112:424-433

Keenan RJ (2015) Climate change impacts and adaptation in forest management: a review. Ann For Sci 72:145-167 
Kellomäki S, Peltola H, Nuutinen T, Korhonen KT, Strandman H (2008) Sensitivity of managed boreal forests in Finland to climate change, with implications for adaptive management. Philosophical Transactions of the Royal Society B: Biological Sciences 363: 2339-2349

Knutti R, Sedláček J (2013) Robustness and uncertainties in the new CMIP5 climate model projections. Nat Clim Chang 3:369-373

Koning J, Winkel G, Sotirov M, Blondet M, Borras L, Ferranti F, Geitzenauer M (2014) Natura 2000 and climate change-polarisation, uncertainty, and pragmatism in discourses on forest conservation and management in Europe. Environ Sci Pol 39:129-138

Kwakkel JH, Walker WE, Haasnoot M (2016) Coping with the wickedness of public policy problems: approaches for decision making under deep uncertainty. J Water Resour Plan Manag 142:01816001

Landmann G, Held A, Schuck A, Van Brusselen J (2015) European forests at risk. A scoping study in support of the development of a European Forest Risk Facility. European Forest Institute. doi:10.13140/RG.2.1.1927.2169

Lawler JJ (2009) Climate change adaptation strategies for resource management and conservation planning. Ann N Y Acad Sci 1162:79-98

Lempert RJ, Collins MT (2007) Managing the risk of uncertain threshold responses: comparison of robust, optimum, and precautionary approaches. Risk Anal 27:1009-1026

Lempert RJ, Popper SW, Bankes SC (2003) Shaping the next one hundred years: new methods for quantitative, long-term policy analysis. MR-1626, RAND, Santa Monica

Lindner M, Lasch P, Erhard M (2000) Alternative forest management strategies under climatic change - prospects for gap model applications in risk analyses. Silva Fennica 34:101-111

Lindner M, Maroschek M, Netherer S, Kremer A, Barbati A, Garcia-Gonzalo J, Seidl R, Delzon S, Corona P, Kolström M, Lexer MJ, Marchetti M (2010) Climate change impacts, adaptive capacity, and vulnerability of European forest ecosystems. For Ecol Manag 259:698-709

Martın-Benito D, Del-Rıo M, Heinrich I, Helle G, Canaellas I (2010) Response of climate-growth relationships and water use efficiency to thinning in a Pinus nigra afforestation. For Ecol Manag 259:967-975

Meehl GA, Washington WM, Arblaster JM, Hu A, Teng H, Kay JE, Gettelman A, Lawrence DM, Sanderson BM, Strand WG (2013) Climate change projections in CESM1 (CAM5) compared to CCSM4. J Clim 26:6287-6308

Meier ES, Lischke H, Schmatz DR, Zimmermann NE (2012) Climate, competition and connectivity affect future migration and ranges of European trees. Glob Ecol Biogeogr 21:164-178

Nabuurs GJ, Lindner M, Verkerk PJ, Gunia K, Deda P, Michalak R, Grassi G (2013) First signs of carbon sink saturation in European forest biomass. Nat Clim Chang 3:792-796

Neuner S, Albrecht A, Cullmann D, Engels F, Griess VC, Hahn WA, Hanewinkel M, Härtl F, Kölling C, Staupendahl K, Knoke T (2015) Survival of Norway spruce remains higher in mixed stands under a dryer and warmer climate. Glob Chang Biol 21:935-946

Palma CD, Nelson JD (2009) A robust optimization approach protected harvest scheduling decisions against uncertainty. Can J For Res 39:342-355

Pasalodos-Tato M, Mäkinen A, Garcia-Gonzalo J, Borges JG, Lämås T, Eriksson LO (2013) Assessing uncertainty and risk in forest planning and decision support systems: review of classical methods and introduction of new approaches. Forest Systems 22:282-303

Petucco C, Abildtrup J, Stenger A (2015) Influences of nonindustrial private forest landowners' management priorities on the timber harvest decision - a case study in France. J For Econ 21:152-166

Puettmann KJ, Messier C, Coates KD (2013) Managing forests as complex adaptive systems: Building resilience to the challenge of global change. Routledge Pubs, London, New York, p 368
Rigling A, Bigler C, Eilmann B, Feldmeyer-Christe E, Gimmi U, Ginzler C, Graf U, Mayer P, Vacchiano G, Weber P, Wohlgemuth T, Zweifel R, Dobbertin M (2013) Driving factors of a vegetation shift from Scots pine to pubescent oak in dry Alpine forests. Glob Chang Biol 19:229-240. doi:10.1111/gcb.12038

San-Miguel-Ayanz S, Manuel-Moreno J, Camia A (2013) Analysis of large fires in European Mediterranean landscapes: lessons learned and perspectives. For Ecol Manag 294:11-22

Sauter PA, Mußhoff O, Möhring B, Wilhelm S (2016) Faustmann vs. real options theory - an experimental investigation of foresters' harvesting decisions. J For Econ 24:1-20

Schelhaas MJ, Nabuurs GJ, Hengeveld G, Reyer C, Hanewinkel M, Zimmermann NE, Cullmann D (2015) Alternative forest management strategies to account for climate change-induced productivity and species suitability changes in Europe. Reg Environ Chang 15: 1581-1594. doi:10.1007/s10113-10015-10788-Z

Schlyter P, Stjernquist I, Bärring L, Jönsson AM, Nilsson C (2006) Assessment of the impacts of climate change and weather extremes on boreal forests in northern Europe, focusing on Norway spruce. Clim Res 31:75-84

Seidl R, Schelhaas MJ, Lexer MJ (2011) Unraveling the drivers of intensifying forest disturbance regimes in Europe. Glob Chang Biol 17:2842-2852

Seidl R, Schelhaas MJ, Rammer W, Verkerk PJ (2014) Increasing forest disturbances in Europe and their impact on carbon storage. Nat Clim Chang 4:806-810

Sevanto S, McDowell NG, Dickman LT, Pangle R, Pockman WT (2014) How do trees die? A test of the hydraulic failure and carbon starvation hypotheses. Plant, Cell and Environment 37:153-161

Soja AJ, Tchebakova NM, French NHF, Flannigan MD, Shugart HH, Stocks BJ, Sukhinin AI, Parfenova EI, Chapin FS, Stackhouse PWJ (2007) Climate-induced boreal forest change: predictions versus current observations. Glob Planet Chang 56:274-296

Svenning JC, Sandel B (2013) Disequilibrium vegetation dynamics under future climate change. Am J Bot 100:1266-1286

Temperli C, Bugmann H, Elkin C (2012) Adaptive management for competing forest goods and services under climate change. Ecol Appl 22:2065-2077

United Nations Framework Convention on Climate Change (UNFCCC). The Paris Agreement (2015). http://unfccc.int/paris_agreement/ items/9485.php. Accessed: 10 March 2017

van Gameren V, Zaccai E (2015) Private forest owners facing climate change in Wallonia: adaptive capacity and practices. Environ Sci Pol 52:51-60

van Vuuren D, Edmonds J, Kainuma M, Riahi K, Thomson A, Hibbard K, Hurtt G, Kram T, Krey V, Lamarque JF, Masui T, Meinhausen M, Nakicenovic N, Smith S, Rose SK (2011) The representative concentration pathways: an overview. Clim Chang 109:5-31

Wagner S, Nocentini S, Huth F, Hoogstra-Klein M (2014) Forest management approaches for coping with the uncertainty of climate change: trade-offs in service provisioning and adaptability. Ecol Soc 19:32 http://dx.doi.org/10.5751/ES-06213-190132

Wilson JS, Baker PJ (2001) Flexibility in forest management: managing uncertainty in Douglas-fir forests of the Pacific Northwest. For Ecol Manag 145:219-227

Yousefpour R, Hanewinkel M (2016) Climate change and decisionmaking under uncertainty. Current Forestry Reports 2:143-149

Yousefpour R, Jacobsen J, Meilby H, Thorsen B, Hanewinkel M, Oehler K (2012) A review of decision-making approaches to handle uncertainty and risk in adaptive forest management under climate change. Ann For Sci 69:1-15

Zubizarreta-Gerendiain A, Pukkala T, Kellomäki S, Garcia-Gonzalo J, Ikonen VP, Peltola H (2015) Effects of climate change on optimised stand management in the boreal forests of central Finland. Eur J For Res 134:273-280 